\title{
Message from the President
}

It is my privilege to present the first issue of Journal of Advanced Engineering and Computation (JAEC).

JAEC has been founded and published by Ton Duc Thang University (TDTU), a public and autonomous university located in Ho Chi Minh City, Vietnam. JAEC is the second international journal of TDTU; the first one is the Journal of Information and Telecommunication (JIT) which is published in conjunction with the famous British publisher Taylor \& Francis Group.

TDTU's target is to join the top 500 best universities of the world because of its fast and steady growth in Vietnam in all aspects. This shows our solid commitment to the standards of quality assurance in all articles published by JAEC. Authors do not have to pay any fees although their published papers are open to the reader. These play important roles in the plan that JAEC will be able to be indexed in Scopus/ISI databases as soon as possible.

Although JAEC is owned and published by TDTU, the international peer-reviewed process is strictly applied and equal opportunity is a stipulation that all authors are fairly treated. Therefore, all submissions around the world are welcomed. We hope that JAEC is not only a scientific forum for scientists in the fields of engineering and computation but also a bridge between our university and experts worldwide.

I would like to sincerely thank the Chairman of the Editorial Board, Professor Václav Snášel and the Editorial Board for their excellent contributions to this first issue and to JAEC in general. Your cooperation has made JAEC possible.

Prof. Le Vinh Danh

President, Ton Duc Thang University

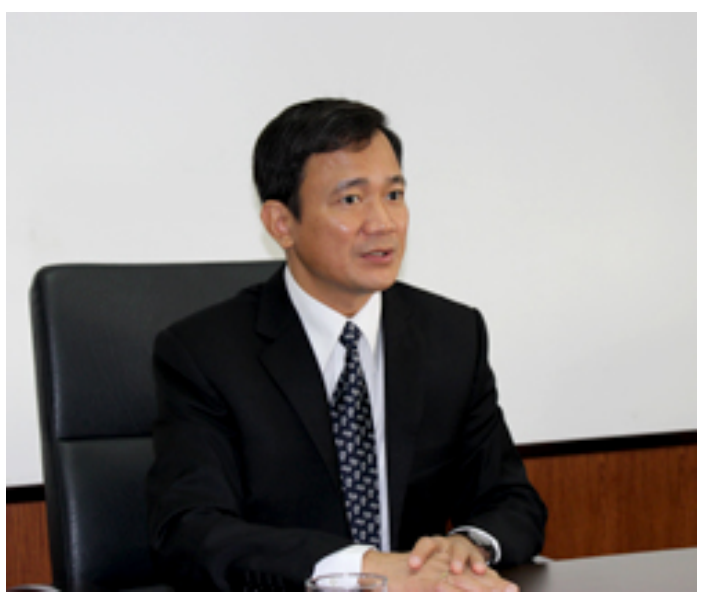

